\title{
Characterization of nerve-induced relaxation of gastrointestinal sphincteric smooth muscle in a South American opossum (Didelphis albiventris)
}

N.M. Matsuda ${ }^{1}$,

R.B. Oliveira ${ }^{2}$ and G. Ballejo ${ }^{1}$

\author{
Departamentos de ${ }^{1}$ Farmacologia e ${ }^{2}$ Clínica Médica, \\ Faculdade de Medicina de Ribeirão Preto, \\ Universidade de São Paulo, 14049-900 Ribeirão Preto, SP, Brasil
}

\author{
Correspondence \\ N.M. Matsuda \\ Departamento de Farmacologia \\ FMRP, USP \\ Av. Bandeirantes, 3900 \\ 14049-900 Ribeirão Preto, SP \\ Brasil \\ E-mail: nmatsuda@usp.br \\ Research supported by FAPESP \\ (No. 95/2544-8) and CNPq. \\ N.M. Matsuda is the recipient \\ of a Postdoctoral fellowship \\ from FAPESP (No. 94/2752-7). \\ R.B. Oliveira and G. Ballejo \\ are recipients of $\mathrm{CNPq}$ \\ fellowships.
}

Received March 8, 1996 Accepted April 7, 1997

\begin{abstract}
The presence of inhibitory nonadrenergic noncholinergic (NANC) intrinsic innervation of the circular muscle of the gastrointestinal sphincters of the South American (SA) opossum was investigated in vitro. Isolated circular muscle strips from the esophagogastric and ileocolonic junctions but not from the gastroduodenal (pylorus) region developed spontaneous tension. Tetrodotoxin (TTX, $1 \mu \mathrm{M})$ augmented the spontaneous tension only in the ileocolonic junction strips. Electrical field stimulation of esophagogastric and ileocolonic junction strips caused frequency-dependent responses consisting of a relaxation at lower frequencies $(<1 \mathrm{~Hz})$ and a biphasic response or contraction at higher frequencies. In the strips from the pyloric region electrical field stimulation abolished the spontaneous activity at lower frequencies and induced contractions at higher frequencies. The responses elicited by electrical field stimulation in the three sphincters were abolished by TTX $(1 \mu \mathrm{M})$. Electrical field-induced contractions were reduced while relaxations were enhanced by atropine $(1 \mu \mathrm{M})$. In the presence of atropine $(1 \mu \mathrm{M})$ and guanethidine $(3 \mu \mathrm{M})$, electrical field stimulation, nicotine and ATP induced frequency- or concentration-dependent relaxations of the three sphincters that were abolished by TTX $(1 \mu \mathrm{M})$. Isoproterenol and sodium nitroprusside caused concentration-dependent relaxations which were TTX-resistant. These findings indicate that the sphincteric circular muscle of the SA opossum gastrointestinal tract is relaxed by the activation of intrinsic NANC nerves and therefore can be used as a model for the study of the mechanisms involved in these responses.
\end{abstract}

Key words

- Nonadrenergic

noncholinergic nerves

- Gastrointestinal sphincter relaxation

- South American opossum 


\section{Introduction}

Nerve-induced relaxation of gastrointestinal smooth muscle is involved in important physiological processes of the digestive tract such as lower esophageal sphincter relaxation following swallowing, accommodation to distention of the proximal stomach and descending inhibition (1). Evidence accumulated during the last three decades indicates that nerves mediating such responses employ neither noradrenaline nor acetylcholine as a neurotransmitter and consequently are referred to as nonadrenergic noncholinergic (NANC) nerves (2). Experiments designed to elucidate the mediator and mechanisms involved in NANC nerve-induced relaxations of sphincteric muscle in the gastrointestinal tract have been performed mainly in North American (NA) opossums (Didelphis virginiana) (3-8) or in dogs (912). The properties of opossum gastrointestinal sphincters are closer to the human ones as compared to dogs and cats (13) but NA opossums are not readily available in Brazil. Consequently, it became of interest to characterize in vitro the neurally induced responses of gastrointestinal sphincters from Didelphis albiventris, an opossum species readily available in South America (SA), in order to determine whether it could be an alternative model to investigate the inhibitory innervation of sphincteric muscle from the gastrointestinal tract.

\section{Material and Methods}

South American opossums (Didelphis albiventris) of both sexes, weighing 500$1500 \mathrm{~g}$, were anesthetized with pentobarbital $(50 \mathrm{mg} / \mathrm{kg}$, ip $)$. Laparotomy was performed and the distal esophagus, stomach and duodenum as well as the distal ileum and proximal colon were resected en bloc and placed in Krebs solution containing 118.5 $\mathrm{mM} \mathrm{NaCl}, 4.7 \mathrm{mM} \mathrm{KCl}, 2.5 \mathrm{mM} \mathrm{CaCl}_{2}, 1.2$ $\mathrm{mM} \mathrm{MgCl} 2,1.2 \mathrm{mM} \mathrm{KH_{2 }} \mathrm{PO}_{4}, 23.8 \mathrm{mM}$
$\mathrm{NaHCO}_{3}$ and $11.1 \mathrm{mM}$ glucose at $37^{\circ} \mathrm{C}$ and bubbled with $95 \% \quad \mathrm{O}_{2} / 5 \% \quad \mathrm{CO}_{2}$. After removal of the mesentery and fat tissue, the esophagogastric, gastroduodenal and ileocolonic junctions were opened longitudinally and cleaned and the mucosa was removed. Mucosa-free strips $(10 \times 3 \times 3 \mathrm{~mm})$ of the circular muscle were cut and suspended in an isolated organ bath filled with $10 \mathrm{ml}$ of modified Krebs solution at $37^{\circ} \mathrm{C}$ bubbled continuously with $95 \% \mathrm{O}_{2} / 5 \% \mathrm{CO}_{2}$. One end of the strip was anchored inside the organ chamber and the other was connected to a force transducer for the measurement of isometric force on a four-channel HewlettPackard polygraph (model 7754A). Lengthpassive tension relationship experiments were performed by stretching the strips to different lengths (monitored by the basal tension) and recording the tension after an equilibration period of $30-45 \mathrm{~min}$ to establish the optimal length. Once the optimal length was determined, in all the experiments in which the responses to electrical field stimulation (EFS) and drugs were characterized the strips were submitted to an initial tension of $1.5 \mathrm{~g}$ and an equilibration period of $45 \mathrm{~min}$. Responses to EFS were elicited by applying $0.5-\mathrm{ms}$ square wave pulses, supramaximal voltage $(40 \mathrm{~V})$ and varying frequencies $(0.1-8 \mathrm{~Hz})$ for $10 \mathrm{~s}$ delivered with a Grass S4C stimulator through two platinum ring electrodes placed $20 \mathrm{~mm}$ apart above and below the muscle strip. The interval between successive stimuli was at least $2 \mathrm{~min}$.

The drugs used were atropine sulfate, propranolol hydrochloride, hexamethonium bromide, prazosin, tetrodotoxin (TTX), guanethidine, isoproterenol, nicotine, adenosine triphosphate disodium salt (ATP), vasoactive intestinal peptide (VIP), $\gamma$-aminobutyric acid (GABA), and sodium nitroprusside (SNP) (all from Sigma Chemical Co., St. Louis, MO). All drugs were dissolved in distilled water and freshly prepared for each experiment. 


\section{Results}

Circular muscle strips from the lower esophageal sphincter and ileocolonic junction always developed spontaneous tension, i.e., tension rose above the passively applied tension, the magnitude of which was related to the initial length of the strip. Maximum tension was developed when the initial length was set at $1.5 \mathrm{~g}$ (about $200 \%$ of the strip length). In contrast, though the pyloric strips did not develop spontaneous tension they also did not exhibit any relaxation after application of the initial tension. In addition, pyloric strips always showed spontaneous phasic activity while ileocolonic junction strips exhibited spontaneous activity that disappeared during the equilibration period. Lower esophageal sphincter strips did not show any spontaneous phasic activity. For all the experiments in which the responses to electrical field stimulation and drugs were characterized the strips were submitted to an initial tension of $1.5 \mathrm{~g}$.

EFS of lower esophageal sphincter and ileocolonic junction strips caused a frequency-dependent response consisting of a relaxation at the lower frequencies $(<1 \mathrm{~Hz})$ and a biphasic response or contraction at the higher frequencies. In the strips from the pyloric region EFS abolished the spontaneous activity at the lower frequencies of stimulation and induced a contraction at higher frequencies (Figures 1A, 2A and 3A). Addition of atropine $(1 \mu \mathrm{M})$ did not affect the tension of the strips in any of the sphincters (2.3 $\mathrm{g} v s 2.4$ for lower esophageal sphincter, $1.5 \mathrm{~g} v s 1.6 \mathrm{~g}$ for pylorus and $2.1 \mathrm{~g} v s 2.0 \mathrm{~g}$ for ileocolonic junction) but was associated with a striking reduction in the magnitude of the contractile response and a corresponding enhancement or unmasking of relaxations in the three sphincters (Figures 1B, 2B and $3 \mathrm{~B})$. Further addition of guanethidine $(3 \mu \mathrm{M})$ did not affect the basal tension or the responses to EFS (Figures 1C, 2C and 3C). Similarly, addition of propranolol $(10 \mu \mathrm{M})$

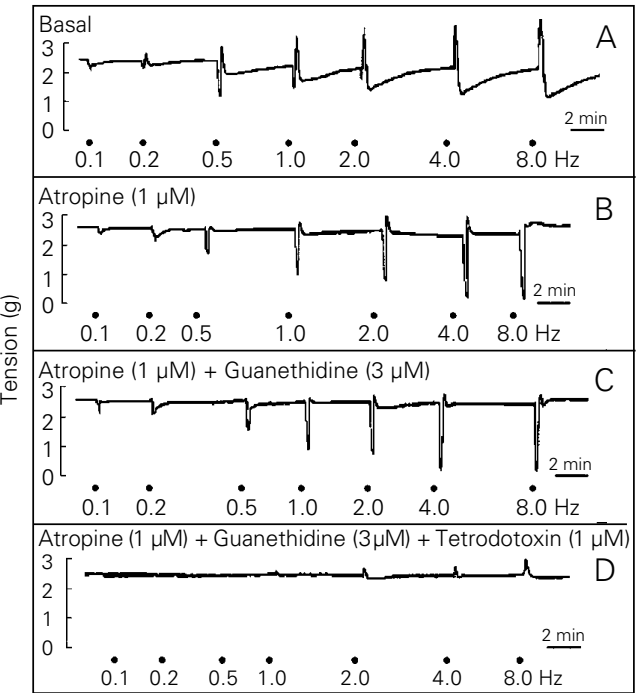

Figure 1 - Representative tracings showing the response of isolated lower esophageal sphincter strips to different EFS frequencies $(0.5 \mathrm{~ms}, 40 \mathrm{~V}$ for 10 $\mathrm{s})$ in the absence (A) or in the presence of atropine (B), atropine + guanethidine $(\mathrm{C})$ or atropine + guanethidine + tetrodotoxin (D). The strips were incubated with the drugs for at least $20 \mathrm{~min}$.

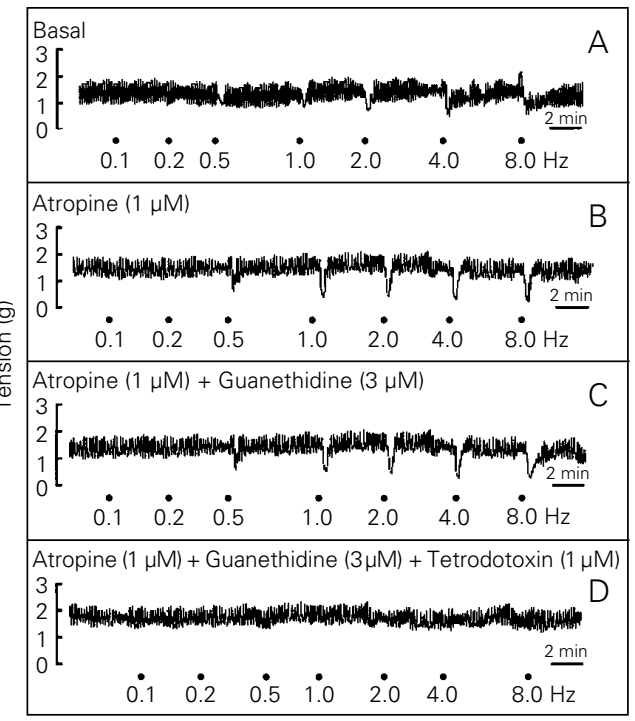

Figure 2 - Representative tracings showing the response of isolated pyloric strips to different EFS frequencies $(0.5 \mathrm{~ms}, 40$ $\mathrm{V}$ for $10 \mathrm{~s}$ ) in the absence (A) or in the presence of atropine (B), atropine + guanethidine (C) or atropine + guanethidine + tetrodotoxin (D). The strips were incubated with the drugs for at least $20 \mathrm{~min}$. or prazosin $(1 \mu \mathrm{M})$ failed to affect the relaxations induced by EFS in the presence of atropine (data not shown). In the presence of atropine and guanethidine, the magnitude of EFS-induced relaxations of the strips from the three sphincters was frequency-dependent, reaching maximal values at $4 \mathrm{~Hz}$ (Figures $1 \mathrm{C}, 2 \mathrm{C}, 3 \mathrm{C}$ and 4$)$. TTX $(1 \mu \mathrm{M})$ abolished the responses to EFS in the three sphincters (Figures 1D, 2D and 3D). Interestingly, TTX raised the basal tension of the ileocolonic junction $(28.7 \pm 8.9 \%)$ but not of the 
Figure 3 - Representative tracings showing the response of isolated ileocolonic junction strips to different EFS frequencies $(0.5 \mathrm{~ms}, 40 \mathrm{~V}$ for $10 \mathrm{~s})$ in the absence $(A)$ or in the presence of atropine (B), atropine + guanethidine $(\mathrm{C})$ or atropine + guanethidine + tetrodotoxin (D). The strips were incubated with the drugs for at least $20 \mathrm{~min}$.
Figure 4 - Relationship between the magnitude of EFS-induced NANC relaxations of isolated lower esophageal sphincter (filled circles) and ileocolonic junction (open circles) strips. Ten-second trains of pulses $(0.5$ $\mathrm{ms}$ and $40 \mathrm{~V}$ ) were applied at 2min intervals at different frequencies. Data are reported as the mean $\pm \operatorname{SEM}(N=8)$. All experiments were performed in the presence of $1 \mu \mathrm{M}$ atropine and $3 \mu \mathrm{M}$ guanethidine which were added 20 min before stimulation. The relaxation magnitude is reported as \% of that obtained with sodium nitroprusside (SNP).
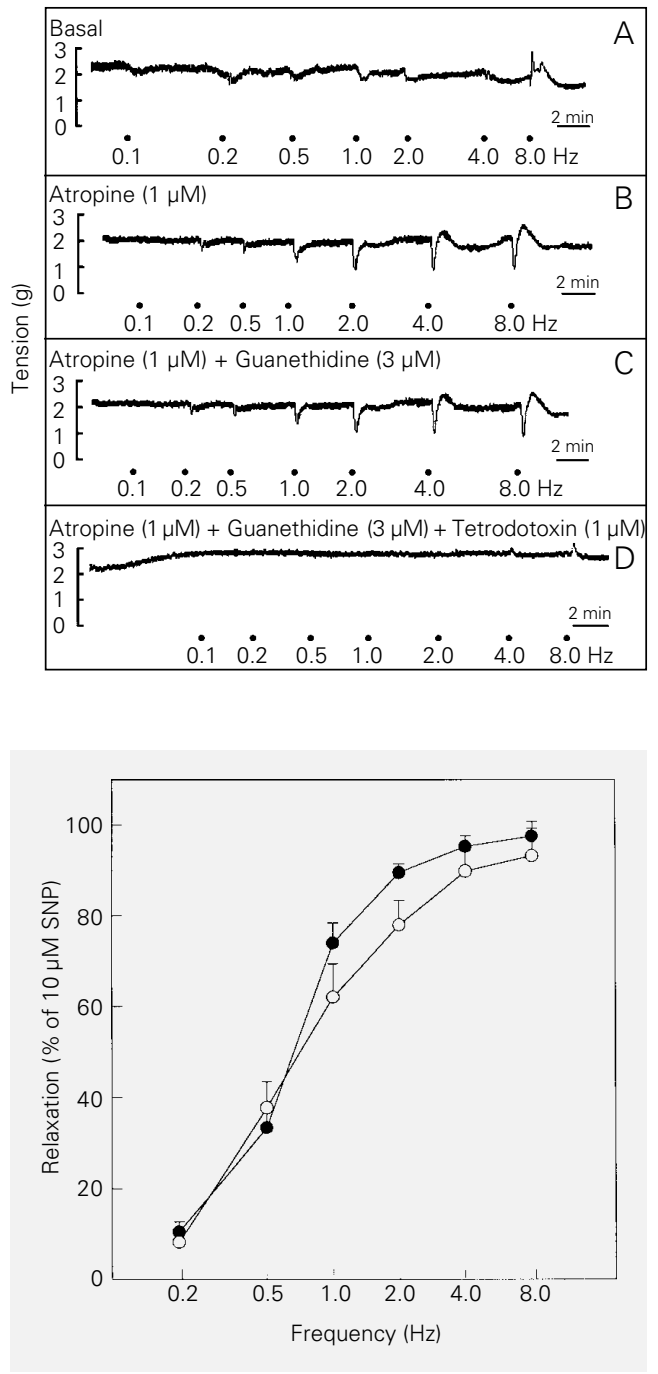

lower esophageal sphincter or the pyloric strips.

In the presence of atropine and guanethidine, nicotine induced concentration-dependent relaxations which were abolished by TTX (Figure 5) and hexamethonium $(10 \mu \mathrm{M})($ data not shown). ATP also caused concentrationdependent relaxations of the lower esophageal sphincter and ileocolonic junction strips in the presence of atropine and guanethidine which were abolished by TTX in the ileocolonic junction but not in lower esophageal sphincter strips (Figure 6). GABA (1-300 $\mu \mathrm{M})$ did not cause any response in the three sphincters (data not shown).

Isoproterenol caused concentration-de- pendent relaxations of the lower esophageal sphincter and ileocolonic junction (Figure 7) which were unaffected by TTX (data not shown). Similarly, VIP and SNP caused concentration-dependent relaxations (data not shown).

\section{Discussion}

It is well established that gastrointestinal smooth muscle contractility is influenced by NANC inhibitory nerves (2). Following the description that the smooth muscle composition of the NA opossum lower esophageal sphincter, in contrast to that of more common laboratory animals (rats, cats and dogs), resembles more closely the human lower esophageal sphincter (13) most of the current concepts regarding the neural control of gastrointestinal sphincters were derived from in vivo and in vitro studies performed on this animal model $(3-8,14,15)$. Since this opossum species is not readily available to us, in the present study we characterized in vitro the nerve-induced responses of the circular smooth muscle from gastrointestinal sphincters of the closely related opossum species Didelphis albiventris, readily available in SA. Our results show that, as described for isolated strips of circular smooth muscle from the esophagogastric and ileocecal junctions of other species including humans (1421 ), the strips from these regions obtained from the SA opossum developed spontaneous tension which was not influenced by atropine or adrenergic blockers. The fact that TTX raised the tension in the ileocolonic junction but not in the lower esophageal sphincter or pyloric strips indicates the presence of an intrinsic tonic inhibitory innervation in this region. Similar responses were reported in the lower esophageal sphincter of the NA opossum (14) as well as in the ileocolonic junction of the cat and NA opossum $(15,16)$. Since atropine and guanethidine did not affect the basal tension of the ileocolonic junction, such tonic innervation 
seems to be due to intrinsic NANC nerves as described in the cat and guinea pig $(16,17)$. The isolated strips of the circular muscle obtained from the pyloric region of SA opossums did not develop spontaneous tension but always exhibited regular spontaneous phasic activity. These findings are similar to those reported for the cat (18) and humans (19). Interestingly, TTX did not affect the basal tension of the pyloric strips, indicating a lack of tonic neural influences.

The present findings also show that electrical field stimulation of isolated circular muscle strips from the lower esophageal sphincter and ileocolonic junction of the SA opossum was associated with relaxation followed by contraction at the higher frequencies of stimulation. Both responses were abolished by TTX indicating that they resulted from the activation of intrinsic nerves. The fact that atropine reduced the EFS-induced contraction and enhanced the magnitude of the relaxant responses in both strips while guanethidine and adrenergic blockers failed to affect the relaxations indicates that the latter are caused by the activation of NANC nerves. Inhibitory NANC nerves of the circular smooth muscle from the lower esophageal sphincter and ileocolonic junction have been described in several species including NA opossums, cats, dogs and humans (20-23). The fact that nicotine also caused relaxations of the lower esophageal sphincter and ileocolonic junction in a hexamethonium- and TTX-sensitive manner suggests that the intrinsic NANC neurons of these regions from the SA opossum are activated by nicotinic receptor stimulation. Circular smooth muscle relaxations due to nicotinic activation of intrinsic NANC neurons have been also reported in the guinea pig taenia coli, rat duodenum and dog ileocolonic junction (24-26). Therefore, the SA opossum is also comparable regarding this characteristic to the more widely employed models for studying inhibitory NANC innervation of gastrointestinal muscle.

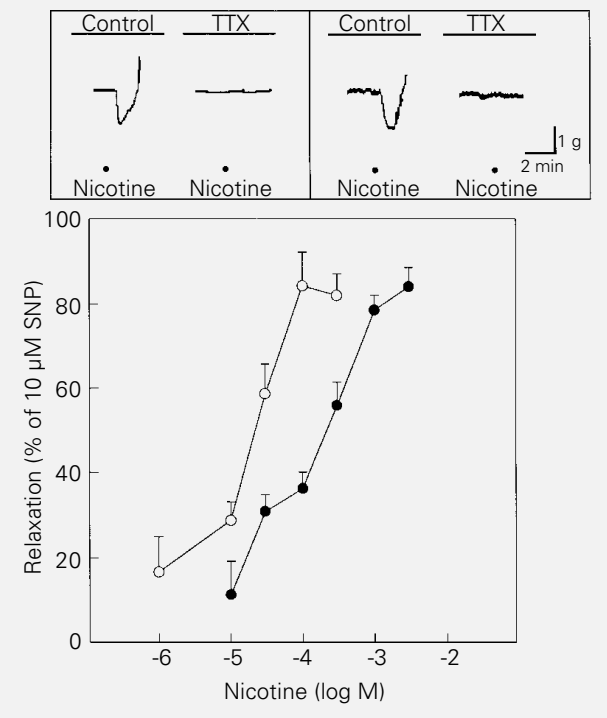

Figure 5 - Top, Representative tracings showing the response elicited by $100 \mu \mathrm{M}$ nicotine on isolated lower esophageal sphincter (left) and ileocolonic junction (right) strips in the absence or in the presence of 1 $\mu \mathrm{M}$ tetrodotoxin (TTX). Bottom, Relationship between the magnitude of relaxations induced by different concentrations (M) of nicotine in isolated lower esophageal sphincter (filled circles) and ileocolonic junction (open circles) strips. Data are reported as the mean $\pm \operatorname{SEM}(N=6)$. The relaxation magnitude is reported as $\%$ of that obtained with sodium nitroprusside (SNP). All experiments were performed in the presence of $1 \mu \mathrm{M}$ atropine and $3 \mu \mathrm{M}$ guanethidine.

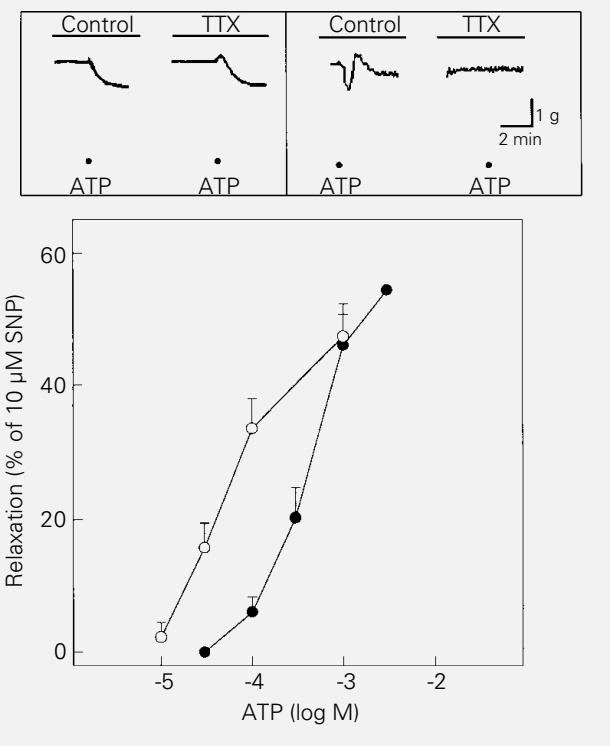

Interestingly, ATP, which has been proposed as a NANC mediator (2), caused TTXsensitive relaxations of the SA opossum ileocolonic junction strips indicating that ATP is not acting directly on smooth muscle. Similar findings were reported for the canine ileocolonic junction (9) and NA opossum lower esophageal sphincter (27). On the other hand, SA opossum lower esophageal sphincter strips were relaxed by ATP in a TTX-
Figure 6 - Top, Representative tracings showing the response elicited by ATP $(300 \mu \mathrm{M})$ on the isolated lower esophageal sphincter (left) and ileocolonic junction (right) strips in the absence or in the presence of 1 $\mu \mathrm{M}$ tetrodotoxin (TTX). Bottom, Relationship between the magnitude of relaxations induced by different concentrations (M) of ATP in isolated lower esophageal sphincter (filled circles) and ileocolonic junction (open circles) strips. Data are reported as the mean \pm SEM $(N=6)$. The relaxation magnitude is reported as \% of that obtained with sodium nitroprusside (SNP). All experiments were performed in the presence of $1 \mu \mathrm{M}$ atropine and $3 \mu \mathrm{M}$ guanethidine. 
Figure 7 - Relationship between the magnitude of relaxation induced by different concentrations (M) of isoproterenol in isolated lower esophageal sphincter (filled circles) and ileocolonic junction (open circles) strips. Data are reported as the mean \pm SEM $(N=6)$. The relaxation magnitude is reported as \% of that obtained with sodium nitroprusside (SNP). All experiments were performed in the presence of 1 $\mu \mathrm{M}$ atropine and $3 \mu \mathrm{M}$ guanethidine.

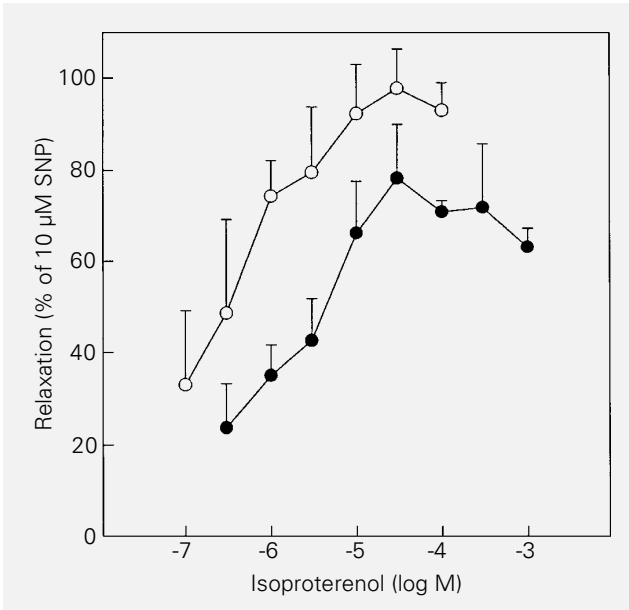

resistant manner. This observation is consistent with the putative role of ATP as an inhibitory NANC neurotransmitter although it is worth remarking that species differences occur, since ATP has been shown to induce contractions in isolated human lower esophageal sphincter strips (28). Isoproterenol, as well as the putative NANC neurotransmitter VIP, caused concentration-dependent relaxations of both lower esophageal sphincter and ileocolonic junction strips in a TTXresistant manner which is consistent with the potential role of the latter as a NANC neurotransmitter.

In conclusion, these findings show that isolated smooth muscle strips from the sphincteric regions of the SA opossum exhibit conspicuous inhibitory NANC nerveinduced responses and could be useful for studies aimed at the identification of the NANC neurotransmitter as well as to elucidate the mechanisms involved in these neurally induced relaxations.

\section{References}

1. Burnstock G \& Costa M (1973). Inhibitory innervation of the gut. Gastroenterology, 64: 141-144

2. Burnstock $G$ (1986). The non-adrenergic non-cholinergic nervous system. Archives Internationales de Pharmacodynamie et de Therapie, 280: 1-15.

3. Goyal RK \& Rattan S (1978). Neurohumoral, hormonal and drug receptors for the lower esophageal sphincter. Gastroenterology, 74: 598-619.

4. Goyal RK, Rattan S \& Said SI (1980). VIP as possible neurotransmitter of noncholinergic nonadrenergic inhibitory neurons. Nature, 288: 378-380.

5. Tottrup A, Svane D \& Forman A (1991). Nitric oxide mediating NANC inhibition in opossum lower esophageal sphincter. American Journal of Physiology, 260: G385-G389.

6. Murray J, Du C, Ledlow A, Bates JN \& Conklin JL (1991). Nitric oxide: mediator of nonadrenergic, noncholinergic responses of opossum esophageal muscle. American Journal of Physiology, 261: G401-G406.

7. Thorphy TJ, Fine CF, Burman M, Barnette MS \& Ormsbee HS (1986). Lower esophageal sphincter relaxation is associated with increased cyclic nucleotide content. American Journal of Physiology, 251: G786-G793.
8. Rattan S \& Thatikunta P (1993). Role of nitric oxide in sympathetic neurotransmission in opossum internal anal sphincter Gastroenterology, 105: 827-836.

9. Boeckxstaens GE, Pelckmans PA, Rampart M, Verbeuren TJ, Herman AG \& Van Maercke YM (1990). Nonadrenergic noncholinergic mechanisms in the ileocolonic junction. Archives Internationales de Pharmacodynamie et de Therapie, 303: 270281.

10. Grous $M$, Ormsbee III H \& Barnette $M$ (1990). Dimethylphenylpiperazinium (DMPP) induced relaxation and elevation of cyclic GMP content in canine lower esophageal sphincter (LES). Biochemical Pharmacology, 40: 1757-1762.

11. Phillips SF, Quigley EM, Kumar D \& Kamath PS (1988). Motility of the ileocoIonic junction. Gut, 29: 390-406.

12. Ward SM, McKeen ES \& Sanders KM (1992). Role of nitric oxide in nonadrenergic, noncholinergic inhibitory junction potentials in canine ileocolonic sphincter. British Journal of Pharmacology, 105: 776782.

13. Christensen J \& Lund GF (1969). Esophageal responses to distension and electrical stimulation. Journal of Clinical Investigation, 48: 408-419.
14. Goyal RK \& Rattan S (1976). Genesis of basal sphincter pressure: Effect of tetrodotoxin on lower esophageal sphincter pressure in vivo. Gastroenterology, 71: 6267.

15. Conklin JL \& Christensen J (1975). Loca specialization at ileocecal junction of the cat and opossum. American Journal of Physiology, 228: 1075-1081.

16. Cardwell BA, Rubin MR, Snape Jr WJ \& Cohen $S$ (1981). Properties of the cat ileocecal sphincter muscle. American Journal of Physiology, 241: G222-G226.

17. Kubota M (1982). Electrical and mechanical properties and neuro-effector transmission in the smooth muscle layer of the guinea-pig ileocecal junction. Pflügers Archiv, European Journal of Pharmacology, 394: 353-361.

18. Bertiger G, Reynolds JC, Ouyang A \& Cohen S (1987). Properties of the feline pyloric sphincter in vitro. Gastroenterology, 92: 1965-1972.

19. Schulze-Delrieu K \& Shirazi SS (1983) Neuromuscular differentiation of the human pylorus. Gastroenterology, 84: 287292.

20. Goyal RK \& Rattan S (1975). Nature of the vagal inhibitory innervation to the lower esophageal sphincter. Journal of Clinical Investigation, 55: 1119-1126. 
21. Christensen S, Conklin J \& Freeman B (1973). Physiological specialization at the esophagogastric junction in three species. American Journal of Physiology, 225: 1265-1270.

22. Tottrup $A$, Forman $A$, Funch-Jensen $P$, Raundahl U \& Anderson KE (1990). Effects of transmural field stimulation in isolated muscle strips from human esophagus. American Journal of Physiology, 258: G344-G351.

23. Tottrup A, Forman A, Uldbjerg N, FunchJensen P \& Anderson KE (1990). Mechanical properties of isolated human esophageal smooth muscle. American Journal of Physiology, 258: G338-G343.
24. Burnstock G, Campbell G \& Rand MJ (1966). The inhibitory innervation of the taenia of the guinea-pig caecum. Journal of Physiology, 182: 504-526.

25. Guimarães CRC, Rodrigues LA, Vettore $O$ \& Antonio $A$ (1988). The relaxing response of the isolated rat duodenum to nicotine. General Pharmacology, 19: 655-659.

26. Pelckmans PA, Boeckxstaens GE, Van Maercke Y, Herman AG \& Verbeuren TJ (1989). Acetylcholine is an indirect inhibitory transmitter in the canine ileocolonic junction. European Journal of Pharmacology, 170: 235-242.
27. Daniel EE, Crankshaw J \& Sarna S (1979). Prostaglandins and tetrodotoxin-insensitive relaxation of opossum lower esophageal sphincter. American Journal of Physiology, 236: E153-E172.

28. Burleigh DE (1979). The effects of drugs and electrical field stimulation on the human lower esophageal sphincter. Archives Internationales de Pharmacodynamie et de Therapie, 240: 169-175. 